\title{
Article
}

\section{Implementation of Multigene Germline and Parallel Somatic Genetic Testing in Epithelial Ovarian Cancer: SIGNPOST Study}

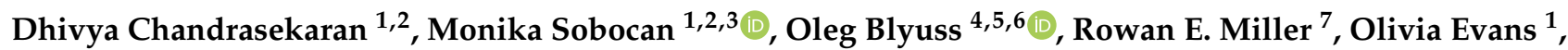 \\ Shanthini M. Crusz ${ }^{7}$, Tina Mills-Baldock ${ }^{8}$, Li Sun ${ }^{1,9}{ }^{\text {, Rory F. L. Hammond }}{ }^{10}$, Faiza Gaba ${ }^{1}$, Lucy A. Jenkins ${ }^{11}$, \\ Munaza Ahmed ${ }^{11}$, Ajith Kumar 11, Arjun Jeyarajah ${ }^{2}$, Alexandra C. Lawrence ${ }^{2}$, Elly Brockbank ${ }^{2}$, \\ Saurabh Phadnis ${ }^{2}$, Mary Quigley ${ }^{8}$, Fatima El Khouly ${ }^{8}$, Rekha Wuntakal ${ }^{12}$, Asma Faruqi ${ }^{10}$, Giorgia Trevisan ${ }^{10}$, \\ Laura Casey ${ }^{10}$, George J. Burghel ${ }^{13}$, Helene Schlecht ${ }^{13}$, Michael Bulman ${ }^{13}$, Philip Smith ${ }^{13}$, Naomi L. Bowers ${ }^{13}$, \\ Rosa Legood ${ }^{9}$, Michelle Lockley ${ }^{14}$, Andrew Wallace ${ }^{13}$, Naveena Singh ${ }^{10}$, D. Gareth Evans ${ }^{13}$ (1) and \\ Ranjit Manchanda $1,2,9, *$ (D)
}

\section{check for} updates

Citation: Chandrasekaran, D.; Sobocan, M.; Blyuss, O.; Miller, R.E.; Evans, O.; Crusz, S.M.; Mills-Baldock, T.; Sun, L.; Hammond, R.F.L.; Gaba, F.; et al. Implementation of Multigene Germline and Parallel Somatic Genetic Testing in Epithelial Ovarian Cancer: SIGNPOST Study. Cancers 2021, 13, 4344. https://doi.org/ $10.3390 /$ cancers 13174344

Academic Editor: Kylie Gorringe

Received: 8 July 2021

Accepted: 24 August 2021

Published: 27 August 2021

Publisher's Note: MDPI stays neutral with regard to jurisdictional claims in published maps and institutional affiliations.

Copyright: (c) 2021 by the authors. Licensee MDPI, Basel, Switzerland. This article is an open access article distributed under the terms and conditions of the Creative Commons Attribution (CC BY) license (https:// creativecommons.org/licenses/by/ $4.0 /)$.
1 Wolfson Institute of Population Health, Barts CRUK Cancer Centre, Queen Mary University of London, Charterhouse Square, London EC1M 6BQ, UK; d.chandrasekaran@qmul.ac.uk (D.C.); m.sobocan@qmul.ac.uk (M.S.); olivia.evans@nhs.scot (O.E.); li.sun1@lshtm.ac.uk (L.S.); f.gaba@qmul.ac.uk (F.G.)

2 Department of Gynaecological Oncology, Barts Health NHS Trust, London EC1 1BB, UK; arjun.jeyarajah@nhs.net (A.J.); alexandra.lawrence5@nhs.net (A.C.L.); elly.brockbank@nhs.net (E.B.); s.phadnis@nhs.net (S.P.)

3 Divison for Gynaecology and Perinatology, University Medical Centre Maribor, 2000 Maribor, Slovenia

4 School of Physics, Engineering and Computer Science, University of Hertfordshire, Hatfield AL10 9AB, UK; o.blyuss@qmul.ac.uk

5 Department of Paediatrics and Paediatric Infectious Diseases, Sechenov First Moscow State Medical University, Moscow 119991, Russia

6 World-Class Research Center "Digital Biodesign and Personalized Healthcare", Sechenov First Moscow State Medical University, Moscow 119991, Russia

7 Department of Medical Oncology, Barts Health NHS Trust, London EC1A 7BE, UK; rowan.miller2@nhs.net (R.E.M.); shanthini.crusz@nhs.net (S.M.C.)

8 Department of Medical Oncology, Barking, Havering \& Redbridge University Hospitals, Essex RM7 0AG, UK tinamills-baldock@nhs.net (T.M.-B.); mary.quigley5@nhs.net (M.Q.); fatima.el-khouly@nhs.net (F.E.K.)

9 Department of Health Services Research, Faculty of Public Health \& Policy, London School of Hygiene \& Tropical Medicine, London WC1H 9SH, UK; rosa.legood@lshtm.ac.uk

10 Department of Pathology, Barts Health NHS Trust, London E1 1FR, UK; r.f.l.hammond@smd14.qmul.ac.uk (R.F.L.H.); asma.faruqi@nhs.net (A.F.); giorgia.trevisan1@nhs.net (G.T.); laura.casey5@nhs.net (L.C.); naveenasingh7@gmail.com (N.S.)

11 North East Thames Regional Genetics Service, Great Ormond Street Hospital, London WC1N 3JH, UK; lucy.jenkins@gosh.nhs.uk (L.A.J.); munaza.ahmed@gosh.nhs.uk (M.A.); ajith.kumar@gosh.nhs.uk (A.K.)

12 Department of Gynaecology, Barking, Havering \& Redbridge University Hospitals, Essex RM7 0AG, UK; r.wuntakal@nhs.net

13 Manchester Centre for Genomic Medicine, Saint Marys Hospital, Manchester M13 9WL, UK; george.burghel@mft.nhs.uk (G.J.B.); helene.schlecht@mft.nhs.uk (H.S.); michael.bulman@mft.nhs.uk (M.B.); philip.smith@mft.nhs.uk (P.S.); Naomi.Bowers@mft.nhs.uk (N.L.B.); andrew.wallace@mft.nhs.uk (A.W.); Gareth.Evans@mft.nhs.uk (D.G.E.)

14 Barts Cancer Institute, Queen Mary University of London, Charterhouse Square, London EC1M 6BQ, UK; m.lockley@qmul.ac.uk

* Correspondence: r.manchanda@qmul.ac.uk

Simple Summary: Multigene testing in ovarian cancer has received increased support due to its applicability for cancer treatment and the impact it has on cancer prevention in families. This study shows that multi-gene germline and somatic testing uptake after counselling by a member of the multidisciplinary cancer clinical team in women with ovarian cancer, was high (97\%). A total of $15.5 \%$ of women were identified to have germline $B R C A 1 / B R C A 2$ pathogenic variants and $7.8 \%$ had somatic $B R C A 1 / B R C A 2$ pathogenic variants. A total of $2.3 \%$ patients had $R A D 51 C / R A D 51 D / B R I P 1$ pathogenic variants. We found that $11 \%$ of germline pathogenic variants were large-genomic-rearrangements 
and were missed by somatic testing. Our findings support prospective parallel somatic-\&-germline panel testing to maximize variant identification.

Abstract: We present findings of a cancer multidisciplinary-team (MDT) coordinated mainstreaming pathway of unselected 5-panel germline BRCA1/BRCA2/RAD51C/RAD51D/BRIP1 and parallel somatic $B R C A 1 / B R C A 2$ testing in all women with epithelial-OC and highlight the discordance between germline and somatic testing strategies across two cancer centres. Patients were counselled and consented by a cancer MDT member. The uptake of parallel multi-gene germline and somatic testing was $97.7 \%$. Counselling by clinical-nurse-specialist more frequently needed $>1$ consultation $(53.6 \%(30 / 56))$ compared to a medical $(15.0 \%(21 / 137))$ or surgical oncologist $(15.3 \%(17 / 110))$ $(p<0.001)$. The median age was $54(\mathrm{IQR}=51-62)$ years in germline pathogenic-variant $(\mathrm{PV})$ versus 61 (IQR $=51-71)$ in BRCA wild-type ( $p=0.001)$. There was no significant difference in distribution of PVs by ethnicity, stage, surgery timing or resection status. A total of $15.5 \%$ germline and $7.8 \%$ somatic BRCA1/BRCA2 PVs were identified. A total of $2.3 \%$ patients had RAD51C/RAD51D/BRIP1 PVs. A total of $11 \%$ germline PVs were large-genomic-rearrangements and missed by somatic testing. A total of $20 \%$ germline PVs are missed by somatic first BRCA-testing approach and $55.6 \%$ germline PVs missed by family history ascertainment. The somatic testing failure rate is higher (23\%) for patients undergoing diagnostic biopsies. Our findings favour a prospective parallel somatic and germline panel testing approach as a clinically efficient strategy to maximise variant identification. UK Genomics test-directory criteria should be expanded to include a panel of OC genes.

Keywords: ovarian cancer; BRCA; genetic testing; germline; somatic; RAD51C; RAD51D; BRIP1

\section{Introduction}

Ovarian cancer (OC) is the leading cause of deaths from gynaecological cancers, with 240,000 new cases and 152,000 deaths occurring worldwide annually [1]. GLOBOCAN data suggest the number of cases from OC will increase by $26 \%$ in the UK and $47 \%$ worldwide, respectively, over the next 20 years [1]. Standard treatment approaches have been associated with limited long-term OC survival of $\sim 30 \%$ [2]. However, the progress over the last 10-15 years has provided the foundations for a precision medicine [3] approach for OC management, involving inherited cancer susceptibility genes. BRCA1/BRCA2 pathogenic and likely pathogenic variants (henceforth termed 'pathogenic variants' or 'PVs') account for most of the known inheritable risk of OC. Around 11-18\% of OC have germline $B R C A 1 / B R C A 2 \mathrm{PV}$ and another $6-9 \%$ have a somatic $B R C A 1 / B R C A 2 \mathrm{PV}$ in the tumour tissue alone which is not inherited. Women with germline BRCA1/BRCA2 PVs have a cumulative risk by age 80 of $17-44 \%$ for developing EOC and $69-72 \%$ for developing breast cancer (BC) [4].

Genetic testing for OC susceptibility genes has recently received an impetus through increasing applicability for cancer treatment and eligibility for clinical trials. The proteins coded by $B R C A 1 / B R C A 2$ are essential in the homologous recombination repair (HRR) of double stranded DNA breaks, whilst PARP (poly ADP ribose polymerase) is an essential component of single-strand DNA repair. Inhibition of PARP increases double strand breaks and prevents HRR deficient (HRD) tumour cells from surviving chemotherapy induced DNA damage, leading to synthetic lethality [5]. Germline as well as somatic BRCA mutated OC have been shown to benefit from 'PARP inhibitor' (PARP-i) therapy with improved progression free survival at both recurrent and more recently primary settings [5-9]. Therefore, knowledge of $B R C A$ status at the time of diagnosis has become pivotal in the guidance of treatment options. Genetic testing for germline BRCA1/BRCA2 PVs in EOC was commissioned by NHS-England in 2015 [10], and has been recommended by other published guidelines over the last few years [11]. More recently, the American Society of Clinical Oncology (ASCO) [12], the British Gynaecological Cancer Society (BGCS) [13] and 
the European Society of Medical Oncology (ESMO) [14] have advocated for somatic testing too.

However, HRD can arise through somatic and germline PV in a wide range of OC susceptibility genes [15]. Approximately 50\% of high-grade serous OC are characterised by HRD suggesting additional mechanisms other than BRCA mutations play a significant role [14]. HRD assays are now available and are beginning to be used in clinical practice [14]. Further moderate risk OC susceptibility genes in the HRR pathway, such as, RAD51C, RAD51D and BRIP1 with lifetime OC-risks of 5.8 to $13 \%$ have been identified and their risks validated [16,17]. Testing for additional genes of clinical utility [18] can lead to wider therapeutic benefit. ASCO now recommends germline $B R C A$ testing within the context of a multigene panel [12]. In addition to targeted therapy, identification of PVs offers opportunities for cancer surveillance and prevention for secondary cancers in index patients as well as cascade testing in relatives. Unaffected relatives with PVs can access relevant surgical prevention and screening options which have well established clinical benefit. This includes risk-reducing salpingo-oophorectomy (RRSO) to reduce their OC risk [19,20]; MRI/mammography screening, or risk reducing mastectomy (RRM) [21], or chemoprevention with selective oestrogen receptor modulators (SERM) to reduce their BC risk [22].

Over recent years, many models of care delivery for OC genetic testing have been implemented into clinical practice [23-25]. There has been great variation in these clinical pathways, with strategies varying with respect to (a) whom to test (unselected or restricted by histology such as for high-grade serous OC or restricted by age, such as under 70 years); (b) what to test (either germline only, or somatic only, or both) and (c) in which order to test (parallel or sequential); (d) which genes to test (BRCA only or multiple genes); and (e) who provides counselling and testing (genetics teams in genetics clinics, genetics professional embedded in oncology clinics, medical oncologists, surgical oncologists, or clinical nurse specialists (CNS)). Despite guidelines, historically, the overall uptake and access to genetic testing across health systems has remained poor, with only $20-30 \%$ eligible patients accessing testing $[26,27]$. Obstacles to introducing routine somatic testing at diagnosis have been attributed to reasons like cost, access/availability of validated somatic testing in a National Health Service (NHS) accredited laboratory and additional resources required to process tumour samples [28]. Most studies to date report clinical experience of implementing BRCA testing. Reports of systematic prospective parallel germline panel and somatic genetic testing are limited. We present our experience and findings of implementing a cancer multidisciplinary team (MDT) coordinated mainstreaming pathway of unselected 5-panel germline $B R C A 1, B R C A 2, R A D 51 C, R A D 51 D, B R I P 1$ and parallel somatic BRCA1/BRCA2 testing in all women with high grade non-mucinous epithelial OC in the Systematic Genetic Testing for Personalised Ovarian Cancer Therapy (SIGNPOST) study (ISRCTN: 16988857) in women from North East London Cancer Network (NELCN). We report on the somatic testing success rates with different types of sample ascertainment. Moreover, importantly we highlight the discordance between germline and somatic testing strategies incorporating testing data from NELCN as well as the Manchester NHS Foundation trust.

\section{Materials and Methods}

\subsection{Pre-Test Counselling and Recruitment}

Women $\geq 18$ years with high-grade non-mucinous epithelial OC, who were newly diagnosed or under follow-up in the NELCN, were offered parallel germline testing for BRCA1, BRCA2, RAD51C, RAD51D, BRIP1 genes and concomitant BRCA1/BRCA2 somatic genetic testing. This was undertaken through the SIGNPOST study (ISRCTN: 16988857). Newly diagnosed patients were identified from gynaecological oncology MDT meetings and consented for genetic testing during their primary treatment. Patients undergoing surveillance post-treatment, were identified through follow-up surgical and medical oncology clinics as well as pathology and clinical databases. Eligibility for genetic testing was established by the treating clinician. Patients received written pre-test education 
information regarding the advantages, disadvantages and implications of genetic-testing. Pre-test genetic counselling and consent was undertaken at routine clinic visits. This was led initially by medical and surgical oncology consultants, and subsequently also undertaken by cancer CNSs. Psychological support was offered by CNSs within the cancer services.

\subsection{Germline and Somatic Testing}

Testing was undertaken by clinically accredited NHS laboratories. A 4 mL EDTA blood sample was taken for germline genetic testing for $B R C A 1, B R C A 2, R A D 51 C, R A D 51 D$ and $B R I P 1$. Germline testing for NELCN samples was undertaken for BRCA1, BRCA2, RAD51C, $R A D 51 D$ and BRIP1 at the North East Thames Regional Genomics Laboratory (Great Ormond Street Hospital), while for Manchester samples testing for BRCA1 and BRCA2 was undertaken at the Genomic Diagnostic Laboratory at the North West Genomic Laboratory Hub. This was carried out using next generation sequencing (NGS; Agilent SureSelect and Illumina NextSeq) of the coding region, sequenced to a minimum depth of 30 reads, including intron/exon splice boundaries. Sanger sequencing was also carried out to confirm variants detected during the NGS screen. Additionally, exon deletions/duplications in $B R C A 1$ and BRCA2 genes were detected using Exome Depth. Multiplex ligation-dependent probe amplification (MLPA; MRC Holland) kits P002-D1 and P090-C1, respectively.

Somatic testing was undertaken using formalin fixed paraffin embedded (FFPE) tissue specimen from diagnostic biopsies, or up front cytoreductive surgery or postchemotherapy cytoreductive surgery as appropriate. FFPE blocks were reviewed by a consultant histopathologist to identify areas with $>20 \%$ tumour content and therefore deemed suitable for somatic testing. The specimens were processed and sent as either $5 \times 5 \mu \mathrm{M}$ thick unstained sections, or as $3 \mathrm{~mm}$ core biopsies from paraffin blocks. Unstained slides were preferred for small volume diagnostic biopsies and in $<20 \%$ neoplastic content. Tumour blocks were selected by the pathologist and graded as $<20 \%, 20-50 \%$ and $>50 \%$ neoplastic content. Testing was undertaken in two NHS accredited diagnostic laboratories. Majority NELCN and Manchester samples were analysed at the Manchester Genomics Laboratory while a few NELCN samples were also tested at the Royal Marsden Hospital laboratory. Detection of variants is dependent on the percentage of tumour infiltration, DNA input concentration and DNA quality. DNA extracted from FFPE tissue was analysed in the coding regions of $B R C A 1$ and $B R C A 2$, using NGS and minimum variant allele depth was $10 \times$. The analysis was performed with Molecular Diagnostics Information Management System v-4.0, based on genome hg19 or GeneRead DNAseq v2 Human Breast Cancer Panel (Qiagen) and Illumina NGS. Mutation and variant calling by custom bioinformatic analysis pipeline validated to detect SNVs and small insertion/deletion mutations (<40 bp) to $5 \%$ mutant allele frequency (MAF).

Variants were classified using the ACGS and CanVIG guidance in force (https:/ / www.acgs.uk.com/quality / best-practice-guidelines / (accessed on 5 January 2021)) [29,30]. Common, high frequency benign and likely benign variants were filtered bioinformatically from a curated list of variants whilst all other variants were assessed by a registered Clinical Scientist. In case of discordance between the germline and somatic samples, a further repeat analysis was undertaken and second report issued. Reports from both germline and somatic tests were sent to the referring clinician for disclosure to the patients.

Validation of $3 \mathrm{~mm}$ FFPE punch biopsies for high-volume somatic testing:

Somatic testing using NGS on FFPE specimens has been validated on $5 \times 5 \mu \mathrm{M}$ thick unstained sections. [31] In order to minimise delay without compromising DNA yield, particularly for archival FFPE tissue, $3 \mathrm{~mm}$ punch biopsies from FFPE tumour blocks were validated for diagnostic somatic testing. Following review by a gynaecological oncology histopathologist, a $5 \mathrm{~mm}$ area with high tumour content $(>20 \%)$ was marked on the Haematoxylin and Eosin (H\&E) stain slide. Keyes punch biopsy (routinely used for skin biopsy) was used to core out $3 \mathrm{~mm}$ sample from corresponding area in FFPE block. 
Five $5 \mu \mathrm{M}$ thick unstained sections were also cut from same block. Five matched $3 \mathrm{~mm}$ cores and unstained sections were compared for DNA yield.

\subsection{Test Result Management}

Most patients including all those diagnosed with a PV were given their test result and counselled in an outpatient clinic by their consenting and treating cancer clinician. A small proportion of patients on long-term follow up declined an additional hospital visit and were given the result by post. All patients with a PV were referred to North East Thames regional genetics service team for additional post-test genetic counselling and facilitating predictive testing in family members.

We report on testing undertaken between $01 / 05 / 2017$ to $31 / 12 / 2019$ across the NELCN, which provides cancer care to a $\sim 1.7 \mathrm{M}$ population covering six NHS hospitals. Patient demographic and clinical data were extracted from electronic patient records, and FH questionnaires completed by the patient. Positive (or strong) FH was defined as any index case of high-grade non-mucinous epithelial OC and breast cancer or epithelial OC in a first-degree or second-degree relative. Patients who had previously undergone genetic testing as they had been referred to clinical genetics in view of a strong $\mathrm{FH}$, were excluded from mainstreaming, but are included in the analysis of prevalence estimates. For the analysis of discordance between germline and somatic $B R C A 1 / B R C A 2$ testing we also include data of 116 unselected OC cases from Manchester NHS Foundation trust who underwent parallel germline and somatic testing. The testing procedures and offer of testing was similarly undertaken in Manchester but germline testing was restricted to $B R C A 1$ and BRCA2.

Descriptive statistics were used for baseline characteristics. PV and wild type groups were compared for ethnicity, age, FH, histology, stage, timing of surgery, chemotherapy response score, and residual disease status. Variables associated with number of pre-test consultations ( 1 or $>1$ ) were explored for type of clinician undertaking counselling, disease status at time of counselling (new diagnosis or on follow up) and treatment status (whether undergoing active treatment or not).

Wilcoxon rank-sum test and Fisher's exact or Chi-square tests were used to test the difference in means and proportions correspondingly. Two-sided $p$-values were reported for all statistical tests. Statistical analysis was undertaken in R version 3.5.1 and SPSS version 26.

\section{Results}

\section{Pathway Development}

Development of the genetic testing pathway was preceded by a wide consultation with the regional clinical geneticists, genetic counsellors, surgical and medical oncologists, CNS, clinical scientists from genetic laboratories, patient representatives and $B R C A$ charity leads. Patient representatives and charity leads expressed a preference for genetic testing to be provided at diagnosis, to be made available all patients including those remained under surveillance post-treatment, and for provision for adequate pre-test counselling and informed consent.

In preparation of a cancer MDT coordinated mainstreaming genetic testing service, all gynaecological cancer MDT members (surgical oncologists, medical oncologist, pathologist and CNS) attended small group teaching sessions led by the regional lead in clinical genetics and a gynaecological oncologist with a long-standing special interest and significant experience in cancer genetics, counselling and testing. This covered principles of Mendelian inheritance, OC susceptibility genes and associated cancer risks; the principles, structure and factors specific to genetic counselling; as well as the developed local testing and referral pathways. Knowledge questionnaires were completed by attendees to ensure appropriate understanding of issues. Following pathway implementation, ongoing professional support for the cancer MDT team was provided by gynaecological cancer precision prevention service, with support from the regional clinical genetics team. Pre-counselling 
written information was developed in collaboration with the major stakeholders and provided to all patients. Additionally, service management meetings across the broader group with representation from medical and surgical oncologist, lead clinical geneticist, clinical scientists from genetic laboratories, lead histopathologist were held every 6-9 months.

Counselling, Recruitment and Genetic Testing:

A total of 310 patients with high-grade non-mucinous epithelial OC who were eligible for genetic testing were identified across the NELCN. This included 188 newly diagnosed women and 122 patients on follow up post-treatment. Of these women seven were excluded: four died prior to commencing treatment, one was unable to consent due to dementia and learning difficulties and two declined genetic testing. The remainder 303 untested patients remained eligible for testing and received pre-test genetic counselling. Of these patients 7/122 (6\%) under surveillance had previously undergone germline BRCA1/BRCA2 mutation testing through clinical genetics due to a strong $\mathrm{FH}$ of $\mathrm{BC}$ or $\mathrm{OC}$ fulfilling prior standard clinical criteria for genetic testing. They were offered and underwent extended panel testing for $R A D 51 C, R A D 51 D$ and BRIP1 along-with somatic testing. Overall, we found a $97.7 \%$ uptake of parallel multi-gene germline and somatic testing via the cancer MDT mediated mainstreaming pathway.

All of the patients were counselled and consented by a member of the cancer MDT, with $45 \%(n=137)$ by a medical oncology member, $36 \%(n=110)$ by a surgical oncology member and $18 \%(n=56)$ by a CNS. The majority required a single pre-test consultation $(78 \%)$ prior to consenting, whereas $18 \%(n=54)$ required two consultations, $4 \%(n=13)$ required three and one patient required four consultations prior to decision to undergo testing (Table 1). The number of pre-test counselling sessions needed varied significantly depending on the clinical professional undertaking counselling. Counselling by CNS was more frequently associated with needing more than one consultation $(53.6 \%(30 / 56))$ compared to counselling by a medical oncologist $(15.0 \%(21 / 137))$ or a surgical gynaeoncologist $(15 \%(17 / 110))(p<0.001)$. The number of consultations required did not significantly differ whether (a) the patient was newly diagnosed or under follow up; and (b) if they were undergoing active treatment or not (Table 1).

Table 1. Factors associated with number of pre-test consultations.

\begin{tabular}{|c|c|c|c|}
\hline Variation & $\begin{array}{c}1 \text { Consultation } \\
n(\%)\end{array}$ & $\begin{array}{c}>1 \text { Consultation } \\
n(\%)\end{array}$ & $p$-Value * \\
\hline \multicolumn{4}{|c|}{ Member of oncology team undertaking pre-test counselling } \\
\hline Medical Oncologist & $116 / 235(49 \%)$ & $21 / 68(30 \%)$ & $<0.001$ \\
\hline Surgical Oncologist & $93 / 235(40 \%)$ & $17 / 68(22 \%)$ & \\
\hline Clinical nurse specialist & $26 / 235(12 \%)$ & $30 / 68(48 \%)$ & \\
\hline \multicolumn{4}{|c|}{ Disease status at the time of counselling } \\
\hline $\begin{array}{l}\text { New diagnosis of ovarian } \\
\text { cancer }\end{array}$ & $127 / 235(54 \%)$ & $40 / 68(59 \%)$ & 0.580 \\
\hline Under follow up & $108 / 235(46 \%)$ & $28 / 68(41 \%)$ & \\
\hline \multicolumn{4}{|c|}{ Treatment status at the time of counselling } \\
\hline Undergoing treatment & $155 / 235(66 \%)$ & $50 / 68(74 \%)$ & 0.303 \\
\hline Not on treatment & $80 / 235(34 \%)$ & $18 / 68(26 \%)$ & \\
\hline
\end{tabular}

Patient demographics and clinical characteristics are summarised in Table 2. The median age at OC diagnosis was 54 years (IQR 51-62) in germline PV compared with 61 (IQR 51-71) in BRCA wild type (BRCA-WT) $(p=0.001)$ patients. In germline $B R C A 1 / B R C A 2 /$ RAD51C/RAD51D/BRIP1 PVs, $44.4 \%(24 / 54)$ had a positive FH compared to $11.3 \%(28 / 249)$ of sporadic tumours $(p<0.001)$ (Table 2$)$. Thus $55.6 \%$ of PVs would have been missed by 
using FH alone. Only 2/7 of RAD51C/RAD51D/BRIP1 PVs had a positive FH. Ethnicity of OC cases included 196 (64.7\%) White, 28 (9.2\%) Black, 52 (17.2\%) South Asian and $27(8.9 \%)$ were classed as 'other'. In women with somatic BRCA1/BRCA2 PV, the median age at diagnosis was 61 (IQR 59-66) and 13\% (2/15) had a positive FH. Most PVs had a highgrade serous (HGS) histology except one BRCA1 with grade 3 endometrioid carcinoma and one BRIP1 with mixed epithelial adenocarcinoma. There was no significant difference in distribution of PVs by ethnicity, stage at diagnosis, timing of surgery or resection status (Table 2). In post-chemotherapy cytoreductive surgery specimens, chemotherapy response score (CRS) of 3 (minimal residual disease) was recorded in 13/69 (18.8\%) germline and somatic PVs compared to $13 / 234(5.6 \%)$ of BRCA-WT tumours $(p=0.025)$.

Table 2. Demographic and clinical characteristics NELCN cohort.

\begin{tabular}{|c|c|c|c|c|}
\hline Category & No Germline Pathogenic Variants & Germline Pathogenic Variants & \multicolumn{2}{|c|}{ Significance } \\
\hline Total & $249 / 303(82.2 \%)$ & $54 / 303(17.8 \%)$ & & \\
\hline \multicolumn{5}{|c|}{ Ethnicity } \\
\hline White & $164 / 249(65.9 \%)$ & $32 / 54(59.3 \%)$ & \multirow{4}{*}{\multicolumn{2}{|c|}{$p=0.515$}} \\
\hline Black & $23 / 249(9.2 \%)$ & $5 / 54(9.3 \%)$ & & \\
\hline South Asian & $39 / 249(15.7 \%)$ & $13 / 54(24.1 \%)$ & & \\
\hline Other & $23 / 249(9.2 \%)$ & $4 / 54(7.4 \%)$ & & \\
\hline \multicolumn{5}{|c|}{ Age in years } \\
\hline Median (IQR) & $61(51-71)$ & $54(51-62)$ & \multicolumn{2}{|c|}{$p<0.001$} \\
\hline \multicolumn{5}{|c|}{ Family History } \\
\hline Positive & $28 / 249(11.2 \%)$ & $24 / 54(44.4 \%)$ & \multirow{2}{*}{\multicolumn{2}{|c|}{$p<0.001$}} \\
\hline Negative & $221 / 249(88.8 \%)$ & $30 / 54(55.6 \%)$ & & \\
\hline \multicolumn{5}{|c|}{ Histology } \\
\hline HGSC & $207 / 249(83.1 \%)$ & $52 / 54(96.3 \%)$ & \multirow{2}{*}{\multicolumn{2}{|c|}{$p=0.010$}} \\
\hline All others & $42 / 249(16.9 \%)$ & $2 / 52(3.7 \%)$ & & \\
\hline \multicolumn{5}{|c|}{ Stage } \\
\hline Early stage & $57 / 249(22.9 \%)$ & $10 / 54(18.5 \%)$ & \multirow{2}{*}{\multicolumn{2}{|c|}{$p=0.589$}} \\
\hline Advanced stage & $192 / 249(77.1 \%)$ & $44 / 54(81.5 \%)$ & & \\
\hline & No Pathogenic Variants & $\begin{array}{c}\text { Total Germline or Somatic Pathogenic } \\
\text { Variants (PV) }\end{array}$ & Germline PV & Somatic PV \\
\hline Total & $234 / 303(77.2 \%)$ & $69 / 303(22.8 \%) *$ & $54 / 303(17.8 \%)$ & $15 / 232(6.5 \%) *$ \\
\hline \multicolumn{5}{|c|}{ Timing of surgery } \\
\hline Primary surgery & $115 / 234(49.1 \%)$ & $30 / 69(43.5 \%)$ & $23 / 54(42.6 \%)$ & $7 / 15(46.7 \%)$ \\
\hline Interval surgery & $69 / 234(29.5 \%)$ & $28 / 69(40.6 \%)$ & $23 / 54(42.6 \%)$ & $5 / 15(33.3 \%)$ \\
\hline Delayed surgery & $12 / 234(5.1 \%)$ & $4 / 69(5.8 \%)$ & $2 / 54(3.7 \%)$ & $2 / 15(13.3 \%)$ \\
\hline \multirow[t]{2}{*}{ no surgery } & $38 / 234(16.1 \%)$ & $7 / 69(10.1 \%)$ & $1 / 54(1.9 \%)$ & $1 / 15(6.7 \%)$ \\
\hline & significance & $p=0.307$ & & \\
\hline \multicolumn{5}{|c|}{ Disease status of ovarian cancer at time of counselling } \\
\hline New diagnosis & $126 / 234(53.8 \%)$ & $41 / 69(59.4 \%)$ & $35 / 54(64.8 \%)$ & $6 / 15(40 \%)$ \\
\hline \multirow[t]{2}{*}{ Under follow up } & $108 / 234(46.2 \%)$ & $28 / 69(40.6 \%)$ & $19 / 54(35.2 \%)$ & $9 / 15(60 \%)$ \\
\hline & significance & $p=0.463$ & & \\
\hline \multicolumn{5}{|c|}{ Chemotherapy response score } \\
\hline 1 & $4 / 234(1.7 \%)$ & 0 & 0 & 0 \\
\hline 2 & $52 / 234(22.2 \%)$ & $13 / 69(18.8 \%)$ & $12 / 54(22.2 \%)$ & $1 / 15(6.7 \%)$ \\
\hline 3 & $13 / 234(5.6 \%)$ & $13 / 69(18.8 \%)$ & $9 / 54(16.7 \%)$ & $4 / 15(26.7 \%)$ \\
\hline \multirow[t]{2}{*}{ Not applicable } & $165 / 234(70.5 \%)$ & $43 / 69(60.0 \%)$ & $33 / 54(61.1 \%)$ & $10 / 15(66.7)$ \\
\hline & significance & $p=0.025$ & & \\
\hline
\end{tabular}


Table 2. Cont.

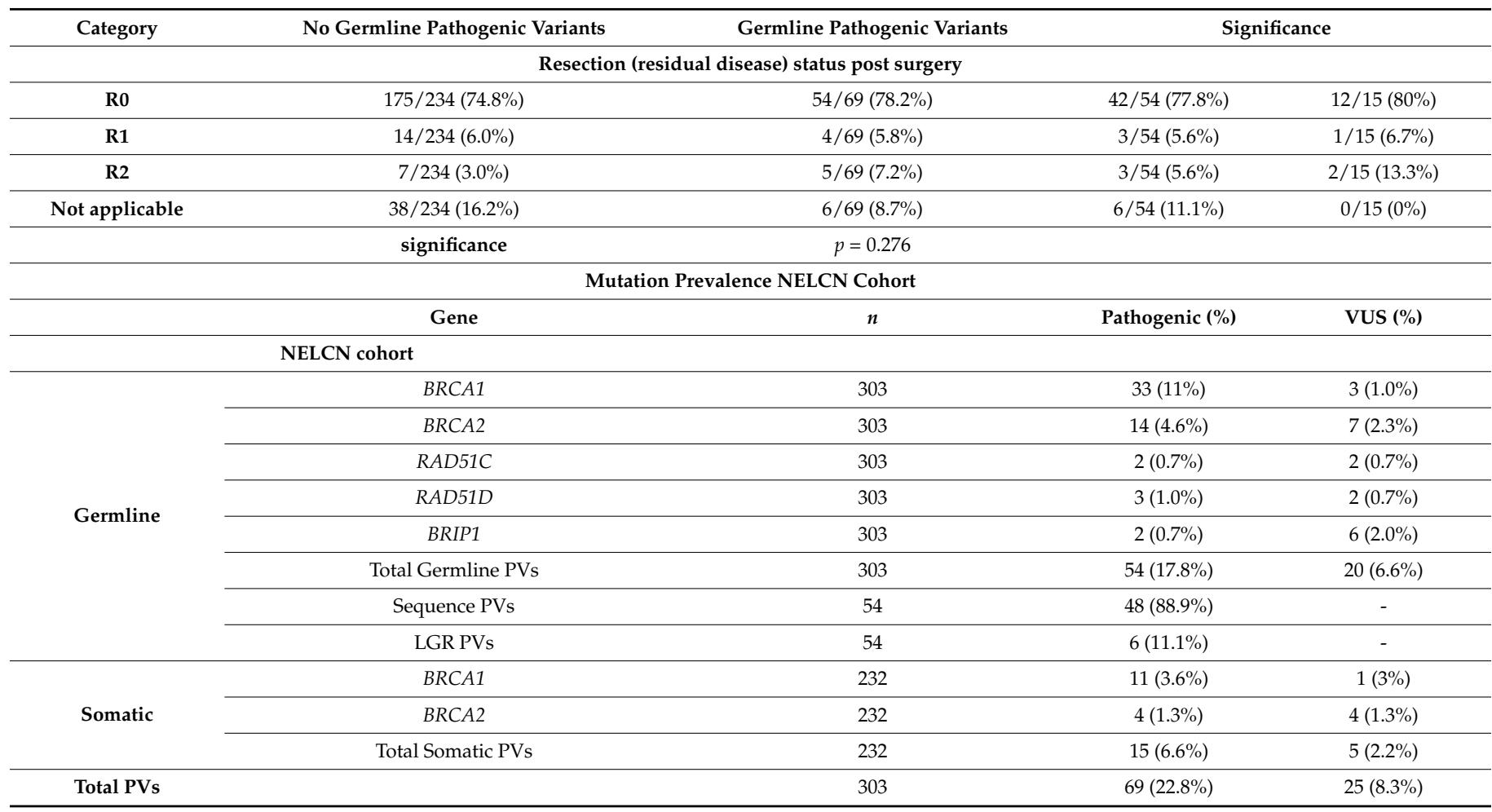

Pathogenic variants = class 4/5 variant in BRCA1, BRCA2, RAD51C, RAD51D, BRIP1. Family history positive = first-degree or second degree relative with ovary and/or breast cancer. HGSC $=$ high grade serous carcinoma. Early stage $=$ stage 1-2; advanced stage $=$ stage 3-4 . $\mathrm{R} 0=$ zero or nil residual disease, $\mathrm{R} 1=\leq 1 \mathrm{~cm}$ residual disease, $\mathrm{R} 2=>1 \mathrm{~cm}$ residual disease. $\mathrm{IQR}=$ inter quartile range, $\mathrm{PV}=\mathrm{Pathogenic}$ variants, VUS = Variants of uncertain significance, LGR- large genomic rearrangements. This table describes outcomes by two groups: (a) with and (b) without germline/somatic pathogenic variants. Two-sided $p$-values were reported for statistical tests comparing these two groups * Results of somatic testing at time of analysis for 71 patients were unavailable (only 232 patients had paired samples). Of these 71 patients 9 had a germline PV.

Validation of $3 \mathrm{~mm}$ FFPE punch biopsies for somatic testing:

Analysis of $3 \mathrm{~mm}$ Keyes punch biopsy and $5 \times 5 \mu \mathrm{M}$ unstained sections from the same FFPE tumour block demonstrated comparable DNA concentration and yield; therefore, archived tumour samples of patients under follow-up were processed as $3 \mathrm{~mm}$ core which proved time-efficient, as it reduced consultant pathologist time needed for review, retrieval and marking of slides. This is therefore likely to be more cost-efficient (Table 3).

Table 3. Comparison of DNA concentration and yield from FFPE $3 \mathrm{~mm}$ core and unstained sections of tumour tissue.

\begin{tabular}{ccccc}
\hline \multirow{2}{*}{ Case ID } & \multicolumn{2}{c}{ DNA Concentration $(\mathrm{ng} / \mu \mathrm{L})$} & \multicolumn{2}{c}{ DNA Yield $(\mu \mathrm{g})$} \\
\cline { 2 - 5 } & Slides & Punch & Slides & Punch \\
\hline Case 1 & 69.35 & 176.4 & 6.94 & 17.64 \\
\hline Case 2 & 40.16 & 60.49 & 4.02 & 6.05 \\
\hline Case 3 & 25.12 & 69.64 & 2.51 & 6.96 \\
\hline Case 4 & 45.19 & 115.9 & 4.52 & 11.59 \\
\hline Case 5 & 54.02 & 41.93 & 5.40 & 4.19 \\
\hline
\end{tabular}

Table 3 describes the validation data of DNA yield from FFPE $3 \mathrm{~mm}$ core biopsies and unstained sections of tumour tissue.

Tumour testing results were available for 232 NELCN cases. Of the 71 cases without tumour testing results, 40 cases lacked available archived tumour tissue for analysis (unable to retrieve from pathology archive or surgery at another cancer centre); and 25 archived cases lacked any tissue with adequate neoplastic content (minimal diagnostic biopsy 
or post-chemotherapy tumour necrosis leaving no viable sample for analysis); and six test results were awaited at the time of analysis (delays due to COVID pandemic). Of these 71 cases without a somatic result, nine had a PV on germline genetic testing (four $B R C A 1$, three $B R C A 2$, one $R A D 51 C$, one RAD51D). Of the 232 NELCN tumour samples that underwent testing, $19(8.9 \%)$ failed analysis due to fragmented DNA or low neoplastic content. Of these failed 19 cases, one had a BRCA1 PV and one a RAD51D PV on germline testing. Further details on tumour tissue processing are provided in Table 4 . The failure rate was higher for diagnostic biopsies $(22.9 \% ; 11 / 48)$ compared to primary cytoreductive surgical specimens $(5.4 \% ; 6 / 110)$ and post-chemotherapy surgical specimens $(2.7 \% ; 2 / 74)$. Primary-surgery specimens that failed analysis were due to fragmented DNA. There were 11 (out of 232) samples categorised with $<20 \%$ neoplastic content, of which five $(45 \%)$ were subsequently found to be adequate for analysis (Table 4). A majority of the samples were sent for analysis as $3 \mathrm{~mm}$ core biopsies from paraffin blocks $(174 / 232,75 \%)$ and the rest as unstained slides (58/232, 25\%). Failure rates were 3/174 (1.7\%) in $3 \mathrm{~mm}$ cores and 16/58 $(27.6 \%)$ in unstained slides, respectively. However, $6 / 16$ failed analysis in the unstained slides group had $<20 \%$ neoplastic content. In our centre, tissue was preferentially sent as unstained slides if neoplastic content was $<20 \%$ or the sample was a small volume diagnostic biopsy.

Table 4. NELCN tumour tissue $B R C A 1 / B R C A 2$ next generation sequencing analysis.

\begin{tabular}{|c|c|c|}
\hline Category & Successfully Reported $(n, \%)$ & Failed Analysis $(n, \%)$ \\
\hline Total number of samples & $213 / 232(91.8 \%)$ & $19 / 232(8.9 \%) *$ \\
\hline \multicolumn{3}{|c|}{ Type of tissue } \\
\hline Pre-chemo diagnostic biopsy & $37 / 48(77.1 \%)$ & $11 / 48(22.9 \%)$ \\
\hline Primary surgery & $104 / 110(94.5 \%)$ & $6 / 110(5.5 \%)$ \\
\hline $\begin{array}{c}\text { Post-chemo cytoreductive } \\
\text { surgery }\end{array}$ & $72 / 74(97.3 \%)$ & $2 / 74(2.7 \%)$ \\
\hline \multicolumn{3}{|c|}{ Type of tumour sample } \\
\hline $3 \mathrm{~mm}$ core from FFPE & $171 / 174(98.3 \%)$ & $3 / 174(1.7 \%)$ \\
\hline $5 \times 5 \mu \mathrm{M}$ unstained slides & $42 / 58(72.4 \%)$ & $16 / 58(27.6 \%)$ \\
\hline \multicolumn{3}{|c|}{ Neoplastic content } \\
\hline$<20 \%$ & $5 / 11(45.5 \%)$ & $6 / 11(54.5 \%)$ \\
\hline $20-50 \%$ & $33 / 40(82.5 \%)$ & $7 / 40(17.5 \%)$ \\
\hline$>50 \%$ & $175 / 181(96.7 \%)$ & $6 / 181(3.4 \%)$ \\
\hline
\end{tabular}

This table describes the results of BRCA testing of tumour tissue in the NELCN cohort. Results are available for 232 cases. * Of the 19 failed analysis, one had a BRCA1 PV and one a RAD51D PV.

Genetic testing results:

Following multi-gene germline testing, 54 germline PVs were identified in 303 women from the NELCN cohort (Supplementary Table S1). Of these PVs, 33 (11\%) were BRCA1; 14 (4.6\%) BRCA2, 2 (0.7\%) RAD51C, 3 (1.0\%) RAD51D and 2 (0.7\%) BRIP1). Six PVs were large genomic rearrangements (LGR) and detected by MLPA: four in BRCA1, one in BRCA2 and one in RAD51C. The germline VUS rate in BRCA1/BRCA2 was $3.3 \%(n=10)$ and $3.3 \%$ $(n=10)$ in RAD51C/RAD51D and BRIP1 (Table 5). Germline BRCA1/BRCA2 testing in the Manchester cases identified $11(9.5 \%)$ PVs, of which $8(6.9 \%)$ were $B R C A 1$ and $3(2.6 \%)$ were $B R C A 2$ PVs (Supplementary Table S1). Additionally, one BRCA1 VUS was identified. The median age of the Manchester cohort was 63 years $(I Q R=55-72)$. Overall, 14 Manchester patients had a strong FH of cancer. Four of the eleven germline PV had a strong FH, while seven lacked a strong $\mathrm{FH}$ and would have been missed without unselected testing. Combining data from NELCN and Manchester series, the total BRCA1/BRCA2 germline PV rate was $15.5 \%(65 / 419)$ and $B R C A 1 / B R C A 2$ germline VUS rate was $2.6 \%(11 / 419)$. 
Table 5. Mutation Prevalence (Manchester cohort).

\begin{tabular}{|c|c|c|c|c|}
\hline & Gene & $n$ & Pathogenic (\%) & VUS (\%) \\
\hline \multicolumn{5}{|c|}{ Manchester Cohort } \\
\hline \multirow{5}{*}{ Germline } & $B R C A 1$ & 116 & $8(6.9 \%)$ & $1(0.9 \%)$ \\
\hline & $B R C A 2$ & 116 & $3(2.6 \%)$ & \\
\hline & Total Germline PVs & & $11(9.5 \%)$ & \\
\hline & Sequence PVs & 11 & $10(90.9 \%)$ & \\
\hline & LGR PVs & 11 & $1(9.1 \%)$ & \\
\hline \multirow{3}{*}{ Somatic } & BRCA1 & 116 & $7(6 \%)$ & $1(0.9 \%)$ \\
\hline & $B R C A 2$ & 116 & $5(4.3 \%)$ & $1(0.9 \%)$ \\
\hline & Total Somatic PVs & & $12(10.3 \%)$ & $2(1.8 \%)$ \\
\hline Total PVs & & 116 & $23(19.8 \%)$ & \\
\hline
\end{tabular}

This table describes the prevalence of variants in the Manchester cohort. VUS-variants of uncertain significance. PV—pathogenic variants. LGR_Large genomic rearrangements.

A total of 232 tumour $B R C A 1 / B R C A 2$ results were available at the time of analysis from NELCN cases. Somatic BRCA1/BRCA2 PVs were detected in $15(6.6 \%)$ cases and the VUS rate was $2.2 \%(n=5)$. Tumour $B R C A 1 / B R C A 2$ testing in 116 Manchester cases identified $7(6 \%) B R C A 1$ and $5(4.3 \%) B R C A 2$ somatic PVs as well as $1(0.9 \%) B R C A 1$ and $1(0.9 \%) B R C A 2$ somatic VUS each (Table 5). The total BRCA1/BRCA2 somatic PV rate was $7.8 \%(27 / 348)$ and somatic VUS rate was $2 \%(7 / 348)$. A germline or somatic PV was identified in $22 \%(92 / 419)$ patients overall. The list of all the variants identified are detailed in Supplementary Table S1. PARP-i treatment was commenced in $49(16 \%)$ NELCN women (27 following primary treatment and 22 following recurrence).

$B R C A 1 / B R C A 2$ germline and somatic PV concordance:

Concordance of $B R C A 1 / B R C A 2 \mathrm{PV}$ identified through germline and tumour testing was explored. This included 232 paired samples with results from NELCN and 116 paired samples with results from Manchester NHS Trust. There were six BRCA1/BRCA2 PVs that showed discordance between germline and tumour testing, five in the NELCN cases and one from the Manchester cases, comprising $10.3 \%$ of all germline PVs. Five of these six $B R C A 1 / B R C A 2$ PVs were LGR that were not detected on somatic testing; one (3\%) germline mutation (from NELCN cases) was initially reported in the somatic report but not in the germline. This mutation was then subsequently identified in the germline following reanalysis of the germline sample. The inability of routine somatic testing to reliably identify LGRs is an important finding with implications for those developing and/or implementing OC mainstreaming pathways and for those whose pathways currently use a somatic testing first triage mechanism. It is critical that patients with LGRs are not missed both from a cancer treatment perspective as well as for precision prevention in unaffected relatives with a PV identified through cascade testing.

Pathway improvements:

Changes to the NELCN pathway were incorporated over time to improve logistic efficiencies, communication between team members and timely communication of result to the patient. These included: agreement on a standardised format for reports received from genomic laboratories and omitting of reporting class- 1 and class- 2 variants. This improved interpretability by cancer clinicians and reduced unnecessary distress in patients.

Initially somatic reports were uploaded as supplementary reports to the original histology result but this caused delays in clinician receiving the information and communicating this to the patient. This was addressed by results being directly sent from the genomic laboratory creating to a shared email-box which was accessed by all members of the clinical team. Responsibility for monitoring and ensuring all results were actioned was subsequently undertaken by the lead medical oncologist. 
Electronic communication with electronic request forms being sent directly to cellular pathology lead scientist rather than to the lead histopathologist, triggered the laboratory technician to pull the relevant blocks and slides for the attention of the gynaecological histopathologist, minimising the delay between clinician request and sample being sent to the genomic laboratory.

The NELCN has a Bengali speaking ethnic minority population, which varies from $3 \%$ to $33 \%$ depending on the borough. All patient facing documents were translated into Bengali to improve engagement and communication with Bengali patients and family members as well as improve decision making. Additionally, a Bengali-speaking clinical member of the extended team, acted as an advocate during genetic counselling.

\section{Discussion}

We demonstrate that unselected concomitant/parallel panel germline and somatic testing at OC diagnosis can be implemented within the NHS setting, and delivered by treating cancer clinicians/professionals through a cancer-MDT coordinated approach. Pretest counselling was undertaken by all members of the cancer MDT team including medical oncologists, surgical oncologists and CNSs. Consistent with other reports of high uptake rates for $B R C A$ testing [23,32-34], we showed this high acceptability extends to panel germline and somatic genetic testing too, with an uptake rate of $97 \%$. PV carriers were younger, more likely to have a strong FH of cancer, HGSC histology and a CRS of 3 at histology. PV status was independent ethnicity, stage at diagnosis, timing of surgery or resection status. We undertook genetic testing prospectively for newly diagnosed patients and also for patients undergoing follow-up. Restricting this to prospective implementation of newly diagnosed cases alone (as has been implemented in some centres) would have missed 19 (19/54, 35.1\%) germline PVs which were detected in the follow-up patients, thus significantly affecting screening/prevention options for these unaffected family members. A total of $56 \%$ of PVs would have been missed by using an FH based approach alone, reconfirming the importance of unselected testing and a mainstreaming approach. This is consistent with reports from others who also showed that around $50 \%$ PVs lacked a strong $\mathrm{FH}$ of $\mathrm{BC}$ or OC $[23,33]$. The BRCA PV prevalence in our NELCN cohort was higher than the Manchester cohort. Some boroughs in North East of London are known to have an Ashkenazi Jewish (AJ) population and the presence of AJ founder mutations in seven NELCN OC cases (Supplementary Table S1) is a contributory factor towards this as $B R C A \mathrm{PV}$ are commoner in AJ compared to non-AJ general population OC cases [35]. We found seven AJ BRCA founder mutations in the NELCN cohort but none of these patients self-reported Jewish ethnicity at recruitment. These patients may have had mixed parentage or grand-parentage and been unaware of their ethnicity or may have preferred not to report/disclose Jewish ethnicity. Additionally, NELCN includes 122 women who had previously been diagnosed and were alive at the time of commencement of the study. Although short term survival for BRCA PV carriers is higher, we did not find the sub-group of 122 women may be enriched for PV.

Our data show that over 1 in $5(22 \%)$ patients have a PV which can affect their treatment, and 1 in 6 have a germline PV which can also affect predictive testing and screening and prevention in unaffected family members. This is consistent with some other reports in the literature $[23,33,36,37]$. Testing for a panel which includes $R A D 51 C$, $R A D 51 D, B R I P 1$ is not currently part of the NHS Genomics test directory and therefore not mandatory across the UK. However, it can if implemented identify an additional 13\% $(7 / 54)$ PVs, with a prevalence of $2.3 \%$ in OC patients, whose families can benefit from precision prevention. Rust et al. showed a slight increase in PVs detected with additional RAD51C/RAD51D testing but this was not completely unselected in their cohort and was undertaken either sequentially or in those with a strong FH [33]. Our data confirm the benefit of amending the UK test directory criteria to offer multi-gene panel testing to all UK women with OC. Our multi-gene germline test includes high- and intermediate risk genes which have already proven clinical utility [38]. A number of commercially available panels 
are available today which test for many more (30-100) genes. However, it is important that only genes of established clinical utility are tested for. We are against indiscriminate panel testing for genes without established clinical utility [39,40]. In addition to RAD51C, RAD51D and BRIP1 genes, it would be appropriate for an OC panel to also include PALB2 and Lynch Syndrome genes going forward. PALB2 has recently been reported as a moderate risk OC gene [41] and Lynch Syndrome (MMR) genes may be found in another $1 \%$ OC patients [42-44]. Some initial reports suggest that cascade testing rates may be lower following mainstreaming compared to testing in clinical genetics [34]. However, all our patients with PVs are reviewed in clinical genetics teams, who are responsible for facilitating cascade testing. Additionally, cascade testing rates are likely to increase with longer follow up.

As multiple genes get incorporated into OC testing panels, the reported VUS rate will also increase. Our germline panel VUS rate was $6.6 \%$ and is comparable to that reported by others $[45,46]$. VUS reporting and subsequent management can pose challenges for counselling, variant monitoring and onwards risk management. This will become an increasingly important issue with widening of the panel of genes tested for [47]. Risk reducing surgery, chemoprevention, screening or downstream predictive testing for unaffected family members, is not recommended in individuals with a VUS. Our report also highlights the importance of uniform classification and standardised reporting of class 3 variants (VUS) across genetic laboratories, including the description in clinical reports issued. The Cancer Variant Interpretation Group UK (CanVIG-UK) now provides an exemplar of a multidisciplinary network addressing this nationally [30]. This improves interpretability of reports by cancer clinicians. Appropriate pre-test education of patients and providers is necessary to limit the harm that could result from VUS misinterpretation. While not of immediate direct relevance, a proportion of VUS will be reclassified in the future to PVs and then have implications for the patients and relatives. This reclassification rate has been reported as around $9 \%$ in a large cohort [48]. In our cohort, a germline mutation BRCA1 c.442-22_442-13del reported in somatic but missed in initial germline (identified in re-analysis of germline) was initially reported as Class 3 VUS and subsequently a year on from testing, was re-classified as a PV.

Strengths of this study include prospective design and systematic approach to include all patients including those on follow up, as well as the high acceptability and uptake rates demonstrated with our pathway and testing process. The upfront staff training implemented across the pathway and continued support provided along-with broad stakeholder engagement contributed to improved patient experience and satisfaction. The extra efforts undertaken to engage with our ethnic minority Bengali population is another strength. In order to broaden access and informed decision making we translated information sheets into local Bengali language and trained a Bangladeshi oncology team member who was instrumental in engaging them in genetic counselling. Our analysis also demonstrates likely success rates for tumour testing for different types of samples which can be helpful for counselling patients and planning services. Limitations include lack of qualitative data and long term follow up data on patient outcomes. These are being collected.

Mainstreaming models such as ours delivered by the cancer MDT team enables implementation of large-scale genetic testing at cancer diagnosis. This approach too can encompass more than one pre-test counselling session where needed. A total of $22 \%$ women needed and received more than one pre-test counselling session in our study. Most other mainstreaming studies do not report on the number of pre-test counselling sessions needed or if multiple were offered. Our clinical nurse specialists favoured utilising more appointments/consultations prior to recruitment. While we did not undertake a formal quantitative assessment of reasons for multiple consultations, colleague feedback indicates these included, some patients needing more time to assimilate information and reflect on it before deciding and/or the need to discuss further with family before decision making; as well as a clinical assessment of not overloading the patient with too much 
information at the first setting especially if they were struggling with managing decision making and information related to their cancer care at the appointment. The issues of some initially long consultations and time pressures in a busy oncology clinic also contributed to this. Other examples of models used to deliver unselected genetic testing at OC diagnosis include a genetics team embedded in oncology clinics, [25] genetic nurse coordinated model [24] and medical oncology [32] delivered testing.

Validation and implementation of $3 \mathrm{~mm}$ cored biopsies from FFPE tumour blocks enabled time- and resource-efficient processing of archived samples. This is particularly suited for archived FFPE tissue (analysis of retrospective cases) and gave a comparable/higher DNA yield than that obtained through slides. Although, we were unable to test $21 \%$ of archived tumour samples, undertaking tumour testing at time of diagnosis for future cases will overcome this. Our pathway now incorporates pathology processing/preparation for genetic testing for all cases at the time of routine histopathology analysis of the initial diagnostic or surgical specimen itself. As a large proportion of failed analysis was pre-treatment diagnostic biopsies, we now routinely obtain additional tissue cores for all women suspected of advanced ovarian malignancy at the time of their diagnostic biopsy. This minimises additional pathology laboratory resources needed and is more cost and time efficient. We also provide estimates of failure rates of diagnostic biopsy ( 23\%), which is relevant for counselling and management of patients planned for neo-adjuvant chemotherapy. NHS Laboratory guidelines suggest the minimum tumour content for NGS somatic/tumour testing referrals should be $20 \%$ [13]. However, we showed benefit of undertaking tumour testing even with $<20 \%$ content in $45 \%$ of such cases. Hence, tumour testing should not be held back in cases with low tumour content as it could be successful in almost half these cases, thus identifying additional women who may benefit from PARP-i treatment.

There has been debate whether both germline and somatic testing should be offered to all; whether unselected germline testing should be offered as first line, followed by somatic testing if germline is negative for PV; or whether reflex somatic testing should be done first, reserving germline if a somatic PV is identified. PVs caused by large genomic rearrangements (LGRs) are missed when PCR-based testing alone is used [49,50]. MLPA is a commonly/routinely used technique to detect LGRs and is found to be highly sensitive and inexpensive [51,52]. LGRs are far more prevalent in BRCA1 than BRCA2 genes and have been reported to account for a wide range of BRCA1 (up to $27 \%$ ) and BRCA2 (up to $11 \%$ ) PVs [53-55]. In a large study, LGRs were reported to constitute around $24 \%$ of $B R C A 1 / B R C A 2$ PVs in high-risk breast/ovarian cancer families, [55] while lower rates are reported in other series and in individuals without strong family histories $[53,55,56]$. Reports suggest significant ethnic variation in the presence of LGR-related PVs: [55] African (2.4\%), Caribbean and Latin American (6.7\%), Danish (9.2\%) and Spanish ancestry (14.5\%) [55-57]. A disadvantage of using an initial tumour/somatic testing triage strategy is the possibility of missing LGRs. The 11\% LGR-rate in our cohort (6/54) is similar to the LGR rate reported in some high-risk breast and ovarian cancer families [54]. In the majority of diagnostic laboratories, NGS tumour/somatic BRCA-testing is not validated for detection of LGRs [50]. While sequential tumour/somatic followed by germline testing may be a less costly approach [58], this strategy runs the risk of missing some germline PVs, particularly LGRs. This can have significant consequences for cancer prevention in families which are missed. Additionally, although reflex tumour testing can identify PVs seen in the germline, up to $31 \%$ of patients found to have a PV in the tumour may not get referred for genetic counselling or germline testing [59]. This highlights a potential limitation of a somatic first strategy, and the need for more robust implementation pathways with built in quality control and fail-safe mechanisms.

In contrast to our findings, a few earlier reports suggest $100 \%$ concordance between somatic and germline testing [45,60,61]. However, the proportion of LGRs amongst the $B R C A$ mutations reported in these studies is unknown, as these have not been described. It is probable/likely that these studies did not have any LGRs in their mutation spectrum. In 
our cohort, somatic BRCA-testing alone, would have missed 9.2\% (4/54) of BRCA1/BRCA2 germline PVs and seven PVs in RAD51C/RAD51D and BRIP1, which comprise $20 \%(11 / 54)$ of germline PVs detected from 5-gene panel testing, who can benefit from targeted therapy and downstream predictive testing.

Germline-testing alone would have missed $2 \%(1 / 54)$ germline BRCA1/BRCA2 PVs, and 15 somatic PVs, comprising 23.1\% (16/69) of all BRCA1/BRCA2 PVs in this cohort, who can benefit from PARP-i treatment. The germline PV missed is an error, which is unlikely to be repeated. A germline first followed by a somatic testing strategy could be an alternative option, but this approach will lead to a longer delay in turn-around times and increase clinician counselling time for giving results as this will need to be done twice. It is also likely to increase the laboratory processing and reporting time and costs, as this is undertaken after initial diagnosis (not contemporaneously with diagnostic reporting). In our experience, a simultaneous or parallel somatic/tumour and germline strategy is a more efficient approach for patients.

\section{Conclusions}

We demonstrate successful implementation of unselected 5-panel germline and concomitant somatic $B R C A 1 / B R C A 2$ testing for patients with OC. BRCA1/BRCA2 germline PVs were identified in $15.5 \%$ patients and BRCA1/BRCA2 somatic PVs in $7.8 \%$. RAD51C/RAD51D/ BRIP1 PVs comprised $13 \%$ of PVs and were identified in an additional $2.3 \%$ patients. A total of $11 \%$ germline PVs are LGRs and are missed by a somatic first testing strategy. A total of $20 \%$ of germline PVs would be missed if somatic BRCA-testing alone was used to triage for germline testing. A total of 55.6\% germline PVs would have been missed by using FH ascertainment alone. The somatic testing failure rate is higher $(23 \%)$ for patients undergoing diagnostic biopsies. Retrospective archival FFPE tissue testing is feasible using $3 \mathrm{~mm}$ punch biopsies from tumour blocks. Our findings favour a prospective parallel somatic and germline panel testing approach as a clinically efficient strategy which maximises variant identification for clinical benefit. The UK Genomics test directory criteria should be expanded to include a panel of OC genes. Formal cost-effectiveness analysis for panel testing is needed and can facilitate wider clinical implementation.

Supplementary Materials: The following are available online at https:/ /www.mdpi.com/article/10 .3390 / cancers13174344/s1, Table S1: List of variants identified through germline and somatic testing.

Author Contributions: Conceptualization, R.M.; methodology, R.M., N.S., R.L., M.L. and D.G.E.; formal analysis, R.M., D.C., O.B. and D.G.E.; Implementation and Investigation, R.M., D.C., R.E.M., S.M.C., A.W., L.A.J., N.S., D.G.E., R.L., A.F., A.J., E.B., A.K., M.L., R.W. and M.Q.; resources, R.M., D.C., R.E.M., M.S., O.E., S.M.C., F.G., R.F.L.H., L.S., L.A.J., M.A., A.K., A.J., A.C.L., E.B., S.P., M.Q., T.M.-B., F.E.K., A.F., L.C., G.T., G.J.B., H.S., M.B., P.S., N.L.B., A.W., N.S. and D.G.E.; data curation, D.C., RM, O.B. and D.G.E.; writing-original draft preparation, R.M., M.S., D.C. and D.G.E.; writing-review and editing, All authors; supervision, R.M.; project administration, R.M., D.C. and M.S.; funding acquisition, R.M. All authors have read and agreed to the published version of the manuscript.

Funding: The study is funded by The Barts Charity, grant ECMG1B6R.

Institutional Review Board Statement: The study was conducted according to the guidelines of the Declaration of Helsinki, and approved by the Ethics Committee of London Riverside Ethics Committee (reference number 17/LO/0405).

Informed Consent Statement: Informed consent was obtained from all study participants.

Data Availability Statement: The data that support the findings of this study are available from the corresponding author, R.M. upon reasonable request.

Acknowledgments: D.G.E. is supported by the Manchester NIHR Biomedical Research Centre (ISBRC-1215-20007). OB thanks the Ministry of Science and Higher Education of the Russian Federation within the framework of state support for the creation and development of World-Class Research Center „Digital biodesign and personalized healthcare” 075-15-2020-926. 
Conflicts of Interest: R.M. declares research funding from Barts and the London Charity and Rosetrees Trust outside this work, an honorarium for grant review from Israel National Institute for Health Policy Research and honorarium for advisory board membership from AstraZeneca/MSD/GSK. R.M. is supported by an NHS Innovation Accelerator (NIA) Fellowship for population testing. The funders had no role in the design of the study; in the collection, analyses, or interpretation of data; in the writing of the manuscript, or in the decision to publish the results. FG declares research funding from The NHS Grampian Endowment Fund, Medtronic and Karl Storz outside this work.

\section{References}

1. International Agency for Research on Cancer. Cancer Tomorrow. In A Tool That Predicts the Future Cancer Incidence and Mortality Burden Worldwide from the Current Estimates in 2018 Up Until 2040; International Agency for Research on Cancer (IARC): Lyon, France, 2018.

2. CRUK. Ovarian cancer statistics. In Ovarian Cancer Incidence; Cancer Research UK: London, UK, 2017.

3. Collins, F.S.; Varmus, H. A new initiative on precision medicine. N. Engl. J. Med. 2015, 372, 793-795. [CrossRef] [PubMed]

4. Kuchenbaecker, K.B.; Hopper, J.L.; Barnes, D.R.; Phillips, K.A.; Mooij, T.M.; Roos-Blom, M.J.; Jervis, S.; van Leeuwen, F.E.; Milne, R.L.; Andrieu, N.; et al. Risks of Breast, Ovarian, and Contralateral Breast Cancer for BRCA1 and BRCA2 Mutation Carriers. JAMA 2017, 317, 2402-2416. [CrossRef] [PubMed]

5. Schettini, F.; Giudici, F.; Bernocchi, O.; Sirico, M.; Corona, S.P.; Giuliano, M.; Locci, M.; Paris, I.; Scambia, G.; De Placido, S.; et al. Poly (ADP-ribose) polymerase inhibitors in solid tumours: Systematic review and meta-analysis. Eur. J. Cancer 2021, 149, 134-152. [CrossRef] [PubMed]

6. Ledermann, J.; Harter, P.; Gourley, C.; Friedlander, M.; Vergote, I.; Rustin, G.; Scott, C.L.; Meier, W.; Shapira-Frommer, R.; Safra, T.; et al. Olaparib maintenance therapy in patients with platinum-sensitive relapsed serous ovarian cancer: A preplanned retrospective analysis of outcomes by BRCA status in a randomised phase 2 trial. Lancet Oncol. 2014, 15, 852-861. [CrossRef]

7. Moore, K.; Colombo, N.; Scambia, G.; Kim, B.G.; Oaknin, A.; Friedlander, M.; Lisyanskaya, A.; Floquet, A.; Leary, A.; Sonke, G.S.; et al. Maintenance Olaparib in Patients with Newly Diagnosed Advanced Ovarian Cancer. N. Engl. J. Med. 2018, 379, $2495-2505$. [CrossRef]

8. Coleman, R.L.; Oza, A.M.; Lorusso, D.; Aghajanian, C.; Oaknin, A.; Dean, A.; Colombo, N.; Weberpals, J.I.; Clamp, A.; Scambia, G.; et al. Rucaparib maintenance treatment for recurrent ovarian carcinoma after response to platinum therapy (ARIEL3): A randomised, double-blind, placebo-controlled, phase 3 trial. Lancet 2017, 390, 1949-1961. [CrossRef]

9. Pujade-Lauraine, E.; Ledermann, J.A.; Selle, F.; Gebski, V.; Penson, R.T.; Oza, A.M.; Korach, J.; Huzarski, T.; Poveda, A.; Pignata, S.; et al. Olaparib tablets as maintenance therapy in patients with platinum-sensitive, relapsed ovarian cancer and a BRCA1/2 mutation (SOLO2/ENGOT-Ov21): A double-blind, randomised, placebo-controlled, phase 3 trial. Lancet Oncol. 2017, 18, 1274-1284. [CrossRef]

10. NHS England. Clinical Commissioning Policy: Genetic Testing for BRCA1 and BRCA2 Mutations; NHS England Specialised Services Clinical Reference Group for Medical Genetics: London, UK, 2015.

11. Practice Bulletin No 182: Hereditary Breast and Ovarian Cancer Syndrome. Obstet. Gynecol. 2017, 130, e110-e126. [CrossRef]

12. Konstantinopoulos, P.A.; Norquist, B.; Lacchetti, C.; Armstrong, D.; Grisham, R.N.; Goodfellow, P.J.; Kohn, E.C.; Levine, D.A.; Liu, J.F.; Lu, K.H.; et al. Germline and Somatic Tumor Testing in Epithelial Ovarian Cancer: ASCO Guideline. J. Clin. Oncol. 2020, 38, 1222-1245. [CrossRef]

13. Sundar, S.; Manchanda, R.; Gourley, C.; George, A.; Wallace, A.; Balega, J.; Williams, S.; Wallis, Y.; Edmondson, R.; Nicum, S.; et al. British Gynaecological Cancer Society/British Association of Gynaecological Pathology consensus for germline and tumour testing for BRCA1/2 variants in ovarian cancer in the United Kingdom. Int. J. Gynecol. Cancer 2021, 31, $272-278$.

14. Miller, R.E.; Leary, A.; Scott, C.L.; Serra, V.; Lord, C.J.; Bowtell, D.; Chang, D.K.; Garsed, D.W.; Jonkers, J.; Ledermann, J.A.; et al. ESMO recommendations on predictive biomarker testing for homologous recombination deficiency and PARP inhibitor benefit in ovarian cancer. Ann. Oncol. 2020, 31, 1606-1622. [CrossRef]

15. Norquist, B.M.; Brady, M.F.; Harrell, M.I.; Walsh, T.; Lee, M.K.; Gulsuner, S.; Bernards, S.S.; Casadei, S.; Burger, R.A.; Tewari, K.S.; et al. Mutations in Homologous Recombination Genes and Outcomes in Ovarian Carcinoma Patients in GOG 218: An NRG Oncology/Gynecologic Oncology Group Study. Clin. Cancer Res. 2018, 24, 777-783. [CrossRef]

16. Ramus, S.J.; Song, H.; Dicks, E.; Tyrer, J.P.; Rosenthal, A.N.; Intermaggio, M.P.; Fraser, L.; Gentry-Maharaj, A.; Hayward, J.; Philpott, S.; et al. Germline Mutations in the BRIP1, BARD1, PALB2, and NBN Genes in Women With Ovarian Cancer. J. Natl. Cancer Inst. 2015, 107, djv214. [CrossRef] [PubMed]

17. Yang, X.; Song, H.; Leslie, G.; Engel, C.; Hahnen, E.; Auber, B.; Horvath, J.; Kast, K.; Niederacher, D.; Turnbull, C.; et al. Ovarian and breast cancer risks associated with pathogenic variants in RAD51C and RAD51D. J. Natl. Cancer Inst. 2020, 112, 1242-1250. [CrossRef] [PubMed]

18. Domchek, S.M.; Robson, M.E. Update on Genetic Testing in Gynecologic Cancer. J. Clin. Oncol. 2019, 37, 2501-2509. [CrossRef] [PubMed]

19. Finch, A.; Beiner, M.; Lubinski, J.; Lynch, H.T.; Moller, P.; Rosen, B.; Murphy, J.; Ghadirian, P.; Friedman, E.; Foulkes, W.D.; et al. Salpingo-oophorectomy and the risk of ovarian, fallopian tube, and peritoneal cancers in women with a BRCA1 or BRCA2 Mutation. JAMA 2006, 296, 185-192. [CrossRef] 
20. Rebbeck, T.R.; Kauff, N.D.; Domchek, S.M. Meta-analysis of risk reduction estimates associated with risk-reducing salpingooophorectomy in BRCA1 or BRCA2 mutation carriers. J. Natl. Cancer Inst. 2009, 101, 80-87. [CrossRef]

21. Rebbeck, T.R.; Friebel, T.; Lynch, H.T.; Neuhausen, S.L.; van 't Veer, L.; Garber, J.E.; Evans, G.R.; Narod, S.A.; Isaacs, C.; Matloff, E.; et al. Bilateral prophylactic mastectomy reduces breast cancer risk in BRCA1 and BRCA2 mutation carriers: The PROSE Study Group. J. Clin. Oncol. 2004, 22, 1055-1062. [CrossRef]

22. Cuzick, J.; Sestak, I.; Bonanni, B.; Costantino, J.P.; Cummings, S.; DeCensi, A.; Dowsett, M.; Forbes, J.F.; Ford, L.; LaCroix, A.Z.; et al. Selective oestrogen receptor modulators in prevention of breast cancer: An updated meta-analysis of individual participant data. Lancet 2013, 381, 1827-1834. [CrossRef]

23. George, A.; Riddell, D.; Seal, S.; Talukdar, S.; Mahamdallie, S.; Ruark, E.; Cloke, V.; Slade, I.; Kemp, Z.; Gore, M.; et al. Implementing rapid, robust, cost-effective, patient-centred, routine genetic testing in ovarian cancer patients. Sci. Rep. 2016, 6 , 29506. [CrossRef]

24. Plaskocinska, I.; Shipman, H.; Drummond, J.; Thompson, E.; Buchanan, V.; Newcombe, B.; Hodgkin, C.; Barter, E.; Ridley, P.; Ng, R.; et al. New paradigms for BRCA1/BRCA2 testing in women with ovarian cancer: Results of the Genetic Testing in Epithelial Ovarian Cancer (GTEOC) study. J. Med. Genet. 2016, 53, 655-661. [CrossRef]

25. Senter, L.; O’Malley, D.M.; Backes, F.J.; Copeland, L.J.; Fowler, J.M.; Salani, R.; Cohn, D.E. Genetic consultation embedded in a gynecologic oncology clinic improves compliance with guideline-based care. Gynecol. Oncol. 2017, 147, 110-114. [CrossRef] [PubMed]

26. Childers, C.P.; Childers, K.K.; Maggard-Gibbons, M.; Macinko, J. National Estimates of Genetic Testing in Women with a History of Breast or Ovarian Cancer. J. Clin. Oncol. 2017, 35, 3800-3806. [CrossRef]

27. Kurian, A.W.; Ward, K.C.; Howlader, N.; Deapen, D.; Hamilton, A.S.; Mariotto, A.; Miller, D.; Penberthy, L.S.; Katz, S.J. Genetic Testing and Results in a Population-Based Cohort of Breast Cancer Patients and Ovarian Cancer Patients. J. Clin. Oncol. 2019, 37, 1305-1315. [CrossRef] [PubMed]

28. Randall, L.M.; Pothuri, B.; Swisher, E.M.; Diaz, J.P.; Buchanan, A.; Witkop, C.T.; Bethan Powell, C.; Smith, E.B.; Robson, M.E.; Boyd, J.; et al. Multi-disciplinary summit on genetics services for women with gynecologic cancers: A Society of Gynecologic Oncology White Paper. Gynecol. Oncol. 2017, 146, 217-224. [CrossRef]

29. Ellard, S.; Baple, E.L.; Berry, I.; Forrester, N.; Turnbull, C.; Owens, M.; Eccles, D.M.; Abbs, S.; Scott, R.; Deans, Z.; et al. ACGS Best Practice Guidelines for Variant Classification in Rare Disease 2020; Association for Clinical Genomic Science (ACGS): London, UK, 2020. Available online: https://www.acgs.uk.com/quality/best-practice-guidelines/ (accessed on 1 May 2021).

30. Garrett, A.; Callaway, A.; Durkie, M.; Cubuk, C.; Alikian, M.; Burghel, G.J.; Robinson, R.; Izatt, L.; Talukdar, S.; Side, L.; et al. Cancer Variant Interpretation Group UK (CanVIG-UK): An exemplar national subspecialty multidisciplinary network. J. Med. Genet. 2020, 57, 829-834. [CrossRef] [PubMed]

31. Ellison, G.; Huang, S.; Carr, H.; Wallace, A.; Ahdesmaki, M.; Bhaskar, S.; Mills, J. A reliable method for the detection of BRCA1 and BRCA2 mutations in fixed tumour tissue utilising multiplex PCR-based targeted next generation sequencing. BMC Clin. Pathol. 2015, 15, 5. [CrossRef] [PubMed]

32. Rumford, M.; Lythgoe, M.; McNeish, I.; Gabra, H.; Tookman, L.; Rahman, N.; George, A.; Krell, J. Oncologist-led BRCA 'mainstreaming' in the ovarian cancer clinic: A study of 255 patients and its impact on their management. Sci. Rep. 2020, 10, 3390. [CrossRef] [PubMed]

33. Rust, K.; Spiliopoulou, P.; Tang, C.Y.; Bell, C.; Stirling, D.; Phang, T.; Davidson, R.; Mackean, M.; Nussey, F.; Glasspool, R.M.; et al. Routine germline BRCA1 and BRCA2 testing in patients with ovarian carcinoma: Analysis of the Scottish real-life experience. BJOG 2018, 125, 1451-1458. [CrossRef]

34. Flaum, N.; Morgan, R.D.; Burghel, G.J.; Bulman, M.; Clamp, A.R.; Hasan, J.; Mitchell, C.L.; Badea, D.; Moon, S.; Hogg, M.; et al. Mainstreaming germline BRCA1/2 testing in non-mucinous epithelial ovarian cancer in the North West of England. Eur. J. Hum. Genet. 2020, 28, 1541-1547. [CrossRef] [PubMed]

35. Modan, B.; Hartge, P.; Hirsh-Yechezkel, G.; Chetrit, A.; Lubin, F.; Beller, U.; Ben-Baruch, G.; Fishman, A.; Menczer, J.; Ebbers, S.M.; et al. Parity, oral contraceptives, and the risk of ovarian cancer among carriers and noncarriers of a BRCA1 or BRCA2 mutation. N. Engl. J. Med. 2001, 345, 235-240. [CrossRef]

36. Rahman, B.; Lanceley, A.; Kristeleit, R.S.; Ledermann, J.A.; Lockley, M.; McCormack, M.; Mould, T.; Side, L. Mainstreamed genetic testing for women with ovarian cancer: First-year experience. J. Med. Genet. 2019, 56, 195-198. [CrossRef] [PubMed]

37. Norquist, B.M.; Harrell, M.I.; Brady, M.F.; Walsh, T.; Lee, M.K.; Gulsuner, S.; Bernards, S.S.; Casadei, S.; Yi, Q.; Burger, R.A.; et al. Inherited Mutations in Women with Ovarian Carcinoma. JAMA Oncol. 2016, 2, 482-490. [CrossRef] [PubMed]

38. Manchanda, R.; Legood, R.; Antoniou, A.C.; Gordeev, V.S.; Menon, U. Specifying the ovarian cancer risk threshold of 'premenopausal risk-reducing salpingo-oophorectomy' for ovarian cancer prevention: A cost-effectiveness analysis. J. Med. Genet. 2016, 53, 591-599. [CrossRef]

39. CDC. ACCE Model Process for Evaluating Genetic Tests. In Genomic Testing; The Office of Public Health Genomics (OPHG), Centers for Disease Control and Prevention (CDC): Atlanta, GA, USA, 2010. Available online: http://www.cdc.gov/genomics/ gtesting/ACCE/ (accessed on 1 January 2021).

40. Burke, W.; Zimmerman, R. Moving beyond ACCE: An Expanded Framework for Genetic Test. Evaluation; PHG Foundation: London, UK, 2007. 
41. Yang, X.; Leslie, G.; Doroszuk, A.; Schneider, S.; Allen, J.; Decker, B.; Dunning, A.M.; Redman, J.; Scarth, J.; Plaskocinska, I.; et al. Cancer Risks Associated with Germline PALB2 Pathogenic Variants: An International Study of 524 Families. J. Clin. Oncol. 2020, 38, 674-685. [CrossRef]

42. Pal, T.; Akbari, M.R.; Sun, P.; Lee, J.H.; Fulp, J.; Thompson, Z.; Coppola, D.; Nicosia, S.; Sellers, T.A.; McLaughlin, J.; et al. Frequency of mutations in mismatch repair genes in a population-based study of women with ovarian cancer. Br. J. Cancer 2012, 107, 1783-1790. [CrossRef]

43. Song, H.; Cicek, M.S.; Dicks, E.; Harrington, P.; Ramus, S.J.; Cunningham, J.M.; Fridley, B.L.; Tyrer, J.P.; Alsop, J.; Jimenez-Linan, M.; et al. The contribution of deleterious germline mutations in BRCA1, BRCA2 and the mismatch repair genes to ovarian cancer in the population. Hum. Mol. Genet. 2014, 23, 4703-4709. [CrossRef]

44. Minion, L.E.; Dolinsky, J.S.; Chase, D.M.; Dunlop, C.L.; Chao, E.C.; Monk, B.J. Hereditary predisposition to ovarian cancer, looking beyond BRCA1/BRCA2. Gynecol. Oncol. 2015, 137, 86-92. [CrossRef] [PubMed]

45. Fumagalli, C.; Tomao, F.; Betella, I.; Rappa, A.; Calvello, M.; Bonanni, B.; Bernard, L.; Peccatori, F.; Colombo, N.; Viale, G.; et al. Tumor BRCA Test for Patients with Epithelial Ovarian Cancer: The Role of Molecular Pathology in the Era of PARP Inhibitor Therapy. Cancers 2019, 11, 1641. [CrossRef] [PubMed]

46. Zuntini, R.; Ferrari, S.; Bonora, E.; Buscherini, F.; Bertonazzi, B.; Grippa, M.; Godino, L.; Miccoli, S.; Turchetti, D. Dealing With BRCA1/2 Unclassified Variants in a Cancer Genetics Clinic: Does Cosegregation Analysis Help? Front. Genet. 2018, 9, 378. [CrossRef] [PubMed]

47. Eccles, D.M.; Mitchell, G.; Monteiro, A.N.; Schmutzler, R.; Couch, F.J.; Spurdle, A.B.; Gomez-Garcia, E.B.; Group, E.C.W. BRCA1 and BRCA2 genetic testing-pitfalls and recommendations for managing variants of uncertain clinical significance. Ann. Oncol. 2015, 26, 2057-2065. [CrossRef]

48. Mersch, J.; Brown, N.; Pirzadeh-Miller, S.; Mundt, E.; Cox, H.C.; Brown, K.; Aston, M.; Esterling, L.; Manley, S.; Ross, T. Prevalence of Variant Reclassification Following Hereditary Cancer Genetic Testing. JAMA 2018, 320, 1266-1274. [CrossRef]

49. Sluiter, M.D.; van Rensburg, E.J. Large genomic rearrangements of the BRCA1 and BRCA2 genes: Review of the literature and report of a novel BRCA1 mutation. Breast Cancer Res. Treat. 2011, 125, 325-349. [CrossRef] [PubMed]

50. Wallace, A.J. New challenges for BRCA testing: A view from the diagnostic laboratory. Eur. J. Hum. Genet. 2016, 24 (Suppl. 1), S10-S18. [CrossRef] [PubMed]

51. Schouten, J.P.; McElgunn, C.J.; Waaijer, R.; Zwijnenburg, D.; Diepvens, F.; Pals, G. Relative quantification of 40 nucleic acid sequences by multiplex ligation-dependent probe amplification. Nucleic Acids Res. 2002, 30, e57. [CrossRef] [PubMed]

52. Bunyan, D.J.; Eccles, D.M.; Sillibourne, J.; Wilkins, E.; Thomas, N.S.; Shea-Simonds, J.; Duncan, P.J.; Curtis, C.E.; Robinson, D.O.; Harvey, J.F.; et al. Dosage analysis of cancer predisposition genes by multiplex ligation-dependent probe amplification. Br. J. Cancer 2004, 91, 1155-1159. [CrossRef]

53. Woodward, A.M.; Davis, T.A.; Silva, A.G.; Kirk, J.A.; Leary, J.A. Large genomic rearrangements of both BRCA2 and BRCA1 are a feature of the inherited breast/ovarian cancer phenotype in selected families. J. Med. Genet. 2005, 42, e31. [CrossRef]

54. James, P.A.; Sawyer, S.; Boyle, S.; Young, M.A.; Kovalenko, S.; Doherty, R.; McKinley, J.; Alsop, K.; Beshay, V.; Harris, M.; et al. Large genomic rearrangements in the familial breast and ovarian cancer gene BRCA1 are associated with an increased frequency of high risk features. Fam. Cancer 2015, 14, 287-295. [CrossRef]

55. Judkins, T.; Rosenthal, E.; Arnell, C.; Burbidge, L.A.; Geary, W.; Barrus, T.; Schoenberger, J.; Trost, J.; Wenstrup, R.J.; Roa, B.B. Clinical significance of large rearrangements in BRCA1 and BRCA2. Cancer 2012, 118, 5210-5216. [CrossRef] [PubMed]

56. Hansen, T.; Jonson, L.; Albrechtsen, A.; Andersen, M.K.; Ejlertsen, B.; Nielsen, F.C. Large BRCA1 and BRCA2 genomic rearrangements in Danish high risk breast-ovarian cancer families. Breast Cancer Res. Treat. 2009, 115, 315-323. [CrossRef]

57. del Valle, J.; Feliubadalo, L.; Nadal, M.; Teule, A.; Miro, R.; Cuesta, R.; Tornero, E.; Menendez, M.; Darder, E.; Brunet, J.; et al. Identification and comprehensive characterization of large genomic rearrangements in the BRCA1 and BRCA2 genes. Breast Cancer Res. Treat. 2010, 122, 733-743. [CrossRef]

58. Kwon, J.S.; Tinker, A.V.; Karsan, A.; Schrader, K.A.; Sun, S. Costs and benefits of tumor testing for mutations in high-grade serous ovarian cancer as a triage for confirmatory genetic testing. Gynecol. Oncol. 2019, 154, 5. [CrossRef]

59. Vlessis, K.; Purington, N.; Chun, N.; Haraldsdottir, S.; Ford, J.M. Germline Testing for Patients With BRCA1/2 Mutations on Somatic Tumor Testing. JNCI Cancer Spectr. 2020, 4, pkz095. [CrossRef]

60. de Jonge, M.M.; Ruano, D.; van Eijk, R.; van der Stoep, N.; Nielsen, M.; Wijnen, J.T.; Ter Haar, N.T.; Baalbergen, A.; Bos, M.; Kagie, M.J.; et al. Validation and Implementation of BRCA1/2 Variant Screening in Ovarian Tumor Tissue. J. Mol. Diagn. 2018, 20, 600-611. [CrossRef] [PubMed]

61. Hauke, J.; Hahnen, E.; Schneider, S.; Reuss, A.; Richters, L.; Kommoss, S.; Heimbach, A.; Marme, F.; Schmidt, S.; Prieske, K.; et al. Deleterious somatic variants in 473 consecutive individuals with ovarian cancer: Results of the observational AGO-TR1 study (NCT02222883). J. Med. Genet. 2019, 56, 574-580. [CrossRef] [PubMed] 